\title{
ChAMBRe: a new atmospheric simulation chamber for aerosol modelling and bio-aerosol research
}

\author{
Dario Massabò $^{1}$, Silvia Giulia Danelli ${ }^{2}$, Paolo Brotto $^{3}$, Antonio Comite ${ }^{4}$, Camilla Costa $^{4}$, Andrea Di Cesare ${ }^{5}$, Jean \\ François Doussin $^{6}$, Federico Ferraro ${ }^{1}$, Paola Formenti ${ }^{6}$, Elena Gatta ${ }^{7}$, Laura Negretti ${ }^{4}$, Maddalena Oliva ${ }^{4}$, \\ Franco Parodi ${ }^{2}$, Luigi Vezzulli ${ }^{5}$, and Paolo Prati ${ }^{1}$ \\ ${ }^{1}$ Dipartimento di Fisica - Università di Genova and INFN - Sezione di Genova, via Dodecaneso 33, 16146, Genoa, Italy \\ ${ }^{2}$ INFN - Sezione di Genova, via Dodecaneso 33, 16146, Genoa, Italy \\ ${ }^{3}$ PM_TEN srl, Piazza della Vittoria 7/14, 16121, Genoa, Italy \\ ${ }^{4}$ Dipartimento di Chimica e Chimica Industriale, Università di Genova, via Dodecaneso 31, 16146, Genoa, Italy \\ ${ }^{5}$ Dipartimento di Scienze della Terra dell' Ambiente e della Vita, Università di Genova, Corso Europa 26, 16132 Genoa, Italy \\ ${ }^{6}$ LISA, UMR CNRS 7583, Université Paris Est Créteil et Université Paris Diderot, Institut Pierre-Simon Laplace, Avenue du \\ Général de Gaulle, 94000 Créteil, France \\ ${ }^{7}$ Dipartimento di Fisica, Università di Genova, via Dodecaneso 33, 16146, Genoa, Italy
}

Correspondence: Dario Massabò (massabo@ge.infn.it)

Received: 3 May 2018 - Discussion started: 23 May 2018

Revised: 9 October 2018 - Accepted: 10 October 2018 - Published: 24 October 2018

\begin{abstract}
Atmospheric simulation chambers are exploratory platforms used to study various atmospheric processes at realistic but controlled conditions. We describe here a new facility specifically designed for the research on atmospheric bio-aerosol as well as the protocols to produce, inject, expose and collect bio-aerosols. ChAMBRe (Chamber for Aerosol Modelling and Bio-aerosol Research) is installed at the Physics Department of the University of Genoa, Italy, and it is a node of the EUROCHAMP-2020 consortium. The chamber is made of stainless steel with a total volume of about $2.2 \mathrm{~m}^{3}$. The lifetime of aerosol particle with dimension from a few hundreds of nanometres to a few microns varies from about 2 to $10 \mathrm{~h}$. Characteristic parts of the facility are the equipment and the procedures to grow, inject, and extract bacterial strains in the chamber volume while preserving their viability. Bacteria are part of the atmospheric ecosystem and have impact on several levels as: health related issues, cloud formation, and geochemistry. ChAMBRe will host experiments to study the bacterial viability vs. the air quality level, i.e. the atmospheric concentration of gaseous and aerosol pollutants. In this article, we report the results of the characterization tests as well as of the first experiments performed on two bacterial strains belonging to the Grampositive and Gram-negative groups. A reproducibility at the
\end{abstract}

$10 \%$ level has been obtained in repeated injections and collection runs with a clean atmosphere, assessing this way the chamber sensitivity for systematic studies on bacterial viability vs. environmental conditions.

\section{Introduction}

\subsection{The problem of bio-aerosol and bacterial strains}

The biological component of atmospheric aerosol (bioaerosol) is a relevant subject of both atmospheric science and biology. From the pioneering investigations at the end of the 19th century (Pasteur, 1862), the study of primary biological aerosol particles (PBAP) has definitively become a multidisciplinary field of research, which requires expertise in physics, chemistry, biology, and medical sciences (Desprès et al., 2012). Among PBAP, bacteria have a crucial role (Bowers et al., 2010). They show atmospheric concentrations from $10^{4}$ to $10^{6}$ cells $\mathrm{m}^{-3}$ (Ligthart, 1997, 2000) with a wide range of diversity (Amato et al., 2007; Burrows et al., 2009b; Gandolfi et al., 2013; Maki et al., 2013). Bacterial viability, including the capability of pathogens to survive in aerosol and maintain their pathogenic potential, de- 
pends on the interaction between bacteria and the other organic and inorganic constituents in the atmospheric medium: such interplay is still far from a satisfactory knowledge and understanding (Jones and Harrison, 2004; Kellogg and Griffin, 2006; Deguillaume et al., 2008; Tang, 2009; Bowers et al., 2010). On the other side, bacteria and PBAP dispersed in the atmosphere can be chemically active (Ariya et al., 2002) and favour the formation of ice and cloud condensation nuclei (Ariya et al., 2009; Hoose et al., 2010; Möhler et al., 2008). Primary biological aerosol particles are generally assumed to be efficient cloud condensation nuclei (CCN), provided that their surfaces are wettable (Després et al., 2012). Bauer et al. (2003) suggested that the chemical composition, structure, and hydrophilicity of the surface layer of bacteria could play important roles in CCN activity. Ariya and Amyot (2004) proposed that bio-aerosols have a potential role in the chemistry of organic compounds in the troposphere via microbiological degradation and hence inducing changes in the ice nucleation (IN) or CCN ability of organics in atmosphere.

So far, PBAP have been studied in-field through a variety of sampling and analysis techniques and addressing their physical, chemical, and biological properties (Reponen et al., 1995; Li and Lin, 1999; Brodie et al., 2007; Georgakopoulos et al., 2009; Fahlgren et al., 2011; Lee et al., 2010; Urbano et al., 2011). The connection between PBAP and dust dispersion and transport over very long distances (Goudie and Middleton, 2006) deserves a particular mention. Dust clouds may contain high concentrations of microbiota, e.g. fungal spores, plant pollen, algae and bacteria. Bio-aerosols associated with dust events can spread pathogens over long distances (Prospero et al., 2005; Griffin, 2007; Nava et al., 2012; Van Leuken et al., 2016) and can impact ecosystem equilibria, human health and yield of agricultural products. For many microorganisms long-range and high-altitude transport in the free atmosphere can be very stressful due to strong ultraviolet radiation, low humidity (inducing desiccation), too low or too high temperatures, and complex atmospheric chemistry (e.g. presence of radicals or other reactive species) (Després et al., 2012; Zhao et al., 2014). Only very resistant organisms are able to survive, so the composition of microbiota can change during the long airborne transport prior to deposition (Meola et al., 2015).

Airborne bacterial communities are highly diverse, and variations in their species diversity are quite complex. The bacterial composition in air is strongly dependent on many factors such as seasonality, meteorological factors, anthropogenic influence, variability of bacterial sources and many other variables. Still, the general trend from available reports is that bacteria found in the air often belong to groups that are also common soil bacteria (e.g. Firmicutes, Proteobacteria, Actinobacteria) (Després et al., 2012). Due to their small size, bacteria have a relatively long atmospheric residence time (on the order of several days or more) compared to larger particles and can be transported over long dis- tances (up to thousands of kilometres). Measurements show that mean concentrations in ambient air can be greater than $1 \times 10^{4}$ cells $\mathrm{m}^{-3}$ over land, whereas concentrations over the sea may be lower by a factor of 100-1000 (Burrows et al., 2009a, b).

Bio-aerosols also seem to play an important role in the reactivity of particulate matter. They can induce reactive oxygen species (ROSs) production and modify particulate matter (PM) toxicity due to their ability to modulate the oxidative potential (OP) of toxic chemicals present in PM (Samake et al., 2017).

Therefore, within the bacterial survival studies there are several interconnected topics. One is related to health issues: exposure to bio-aerosols has been linked to various health effects (disease spreading, e.g. meningitis and bioaero-contamination, like legionella and refrigerating towers. Pearson et al., 2015; Ghosh et al., 2015; Sala Ferré et al., 2009). Another topic is connected to climate and CCN and IN impact, where viability and proliferation of airborne bacteria are the significant investigation subjects (Bauer et al., 2003; Deguillaume et al., 2008; Amato et al., 2015). A biogeochemical issue is related to the long range transport of bacteria and dust events, since bacteria can stick to dust particles and can be more efficiently (i.e. remaining viable) transported over long distances. (Meola et al., 2015; Nava et al., 2012; Van Leuken et al., 2016).

\subsection{Atmospheric simulation chambers and bacteria}

The study of relevant processes taking place in the Earth atmosphere is usually pursued through a wide range of field observations where complicated, unexpected and interconnected effects are often difficult to disentangle. The possibility of planning and performing experiments in controlled conditions is therefore highly desirable. This need has triggered the conception and development of the atmospheric simulation chambers (ASCs in the following), i.e., smallto large-scale facilities (with volumes ranging between a few to hundreds cubic metres), where atmospheric conditions can be maintained and monitored in real time for periods long enough to mimic the realistic environments and to study interactions among their constituents (FinlaysonPitts and Pitts, 2000). ASCs have been used to study chemical and photochemical processes that occur in the atmosphere, such as ozone formation (Carter et al., 2005 and references therein) and cloud chemistry (Wagner et al., 2006) or aerosol-cloud interaction (Benz et al., 2005), but the high versatility of these facilities allows for a wider application covering all fields of atmospheric aerosol science. A full list and review of the approach and of the main facilities around the world can be found in Becker (2006). In Europe, there are several ASCs organized through the network EUROCHAMP-2020 (see all the details at the link https://www.eurochamp.org/default.aspx, last access: 19 October 2018). 
Since the interplay of bio-aerosol and atmospheric conditions is still poorly known, suitable facilities are needed, where transdisciplinary studies gathering atmospheric physics, chemistry, and biology issues are possible.

Experiments conducted inside confined artificial environments where physical and chemical conditions and/or compositions can be controlled, can provide information on bacterial viability, biofilm and spore formation, and endotoxin production. Currently, the literature reports several examples of studies performed in small reactors (Levin et al., 1997; Griffiths et al., 2001; Ho et al., 2001; Ribeiro et al., 2013; Sousa et al., 2012). The use of atmospheric simulation chambers has been much more limited and focused on the interaction of bacteria with atmospheric parameters, regarding bioaerosol release effects (Jones and Harrison, 2004), and on ice nucleation and cloud condensation (Möhler et al., 2008; Bundke et al., 2010; Chou, 2011).

In 2014, some of the co-authors of the present work designed and performed an exploratory experiment (Brotto et al., 2015) at the CESAM (French acronym for the Experimental Multiphasic Atmospheric Simulation Chamber; Wang et al., 2011). On colonies of Bacillus subtilis injected, then extracted from CESAM on Petri dishes, they could observe a clear increase of bacterial viability when concentrations of $\mathrm{NO} / \mathrm{NO}_{2}$ and $\mathrm{CO}_{2}$ were contemporarily maintained inside the simulation chamber at a level of about $35 / 630 \mathrm{ppb}$ and $400 \mathrm{ppm}$, respectively. Bacillus subtilis is a well-known Gram-positive bacterial strain (Burrows et al., 2009b; Gandolfi et al., 2013) and the viability increase observed in the two experiments was by a factor 35 and 10 , respectively (Brotto et al., 2015). Such experimental evidence made clear that the effects of atmospheric pollution on bacteria viability could be studied in atmospheric chambers. In order to perform systematic studies to resolve and describe the physical and chemical mechanisms ruling these interactions, dedicated facilities with a microbiology laboratory linked to the ASC for the handling and characterization of bio-aerosol are needed.

Prompted by the outcomes of pilot experiments (Amato et al., 2015; Brotto et al., 2015), a new dedicated atmospheric chamber, ChAMBRe (Chamber for Aerosol Modelling and Bio-aerosol Research), has been designed and installed in Genoa (Italy). While ChAMBRe, as other ASCs, is a multipurpose facility, the outcomes of the correlation between bacteria viability and atmospheric condition and/or composition will provide the input for developing ad hoc modules to be then implemented in chemical transport models. This can be done following a scheme often used for the chemical mechanisms parameterization (see, for example, the smog chamber experiments used for the evaluation of carbon bond mechanisms in Parikh et al., 2013). Such software tools, are widely used both in scientific research and in air quality evaluations, to predict the fate (i.e. transport, deposition, and chemical changes) of the atmospheric pollutants and, at the moment, they do not include any biological patch.

\section{Description of the facility}

\subsection{ChAMBRe main structure}

ChAMBRe is installed at the ground floor of the building hosting the Department of Physics of the University of Genoa, where it is jointly managed by the Italian National Institute of Nuclear Physics (INFN) and the Physics Department (https://www.labfisa.ge.infn.it/, last access: 19 October 2018). Since the beginning of 2017, ChAMBRe is one of the nodes of the EUROCHAMP-2020 network with specific tasks on bio-aerosol studies.

CHAMBRe has a cylindrical shape with domed bases (Fig. 1). It has maximum height and diameter of 2.9 and $1 \mathrm{~m}$, respectively, and a total volume of $2.23 \mathrm{~m}^{3}$. The latter includes all the secondary volumes connected to the main body and has been determined measuring the volume of air needed to bring the chamber at atmospheric pressure after an evacuation down to $5 \times 10^{-2}$ mbar. The main body is divided into three parts: two domed cylinders (see Fig. 1) connected by a central ring at a $60 \mathrm{~cm}$ height. The lower dome has a bottom aperture with a pass through for the shaft of a fan and two lateral ISO-K250 flanges. The central ring symmetrically allocates six flanges (two with a diameter of $40 \mathrm{~cm}$ and four with a diameter of $10 \mathrm{~cm}$ ). Finally, the top cylinder is equipped with two lateral and symmetrical ISO-K100 flanges plus another flanged aperture (ISO-K250) on the dome. The interior of the chamber can be accessed through the two ISO-K400 flanges or by removing the top dome with a crane. One of the two flanges in the bottom part is connected through a pneumatic valve to a smaller horizontal cylinder (length $=1 \mathrm{~m}$ ), which hosts a movable shelf designed to move specific samples inside the chamber as described in Sect. 4.3. The lower dome is held by a metallic support to maintain the entire structure in vertical position (Fig. 2).

While ChAMBRe has been designed to operate at atmospheric pressure, the second ISO-K250 flange of the lower cylinder is connected to a composite pumping system (a rotary pump model TRIVAC ${ }^{\circledR}$ D65B, Leybold Vacuum, followed by a root pump model RUVAC WAU 251, Leybold Vacuum), which can evacuate the internal volume to a vacuum level of about $5 \times 10^{-2}$ mbar in about 15 mins. A safety valve (Leycon Secuvac DN 63, Oerlikon Leybold Vacuum) is mounted as a gate between the pumping system and ChAMBRE: in the event of a power failure it automatically closes in less than $1 \mathrm{~ms}$, thus preventing possible backwashes of the pumps oil inside the chamber. The return to atmospheric pressure is a two-step procedure: first, pure $\mathrm{N}_{2}$ from a compressed gas cylinder is flushed in, until a pressure of $5 \mathrm{mbar}$ is reached, and then the ambient air can enter the chamber through an absolute HEPA filter (model: PFIHE842, NW25/40 Inlet/Outlet - 25/55 SCFM, $99.97 \%$ efficient at $0.3 \mu \mathrm{m})$ and a zeolite trap (upstream). 


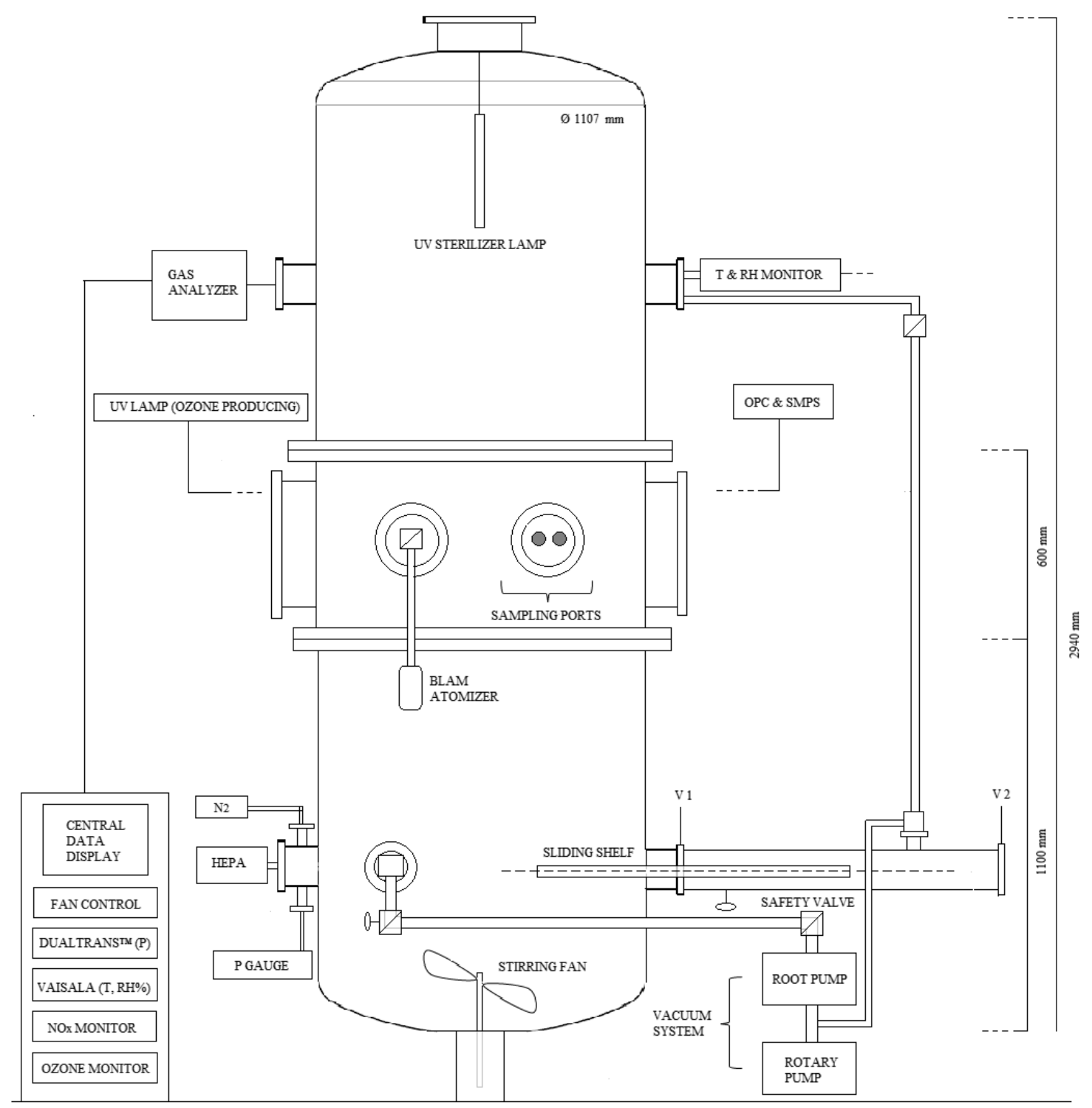

Figure 1. ChAMBRe layout.

\subsection{Basic equipment}

To favour the mixing of the gas and aerosol species in the reactor a fan is installed in the bottom part of the chamber (Fig. 1). It is a standard venting system with four metallic arms of $25 \mathrm{~cm}$ length each connected to an external engine through a rotating shaft. A particular pass through has been designed and built at INFN-Genoa to ensure the vacuum seal. The fan speed can be regulated by an external controller and varied between 0.0 and $50 \mathrm{~Hz}$ in steps of $0.1 \mathrm{~Hz}(0$ to $3000 \mathrm{rpm}$, in steps of $6 \mathrm{rpm}$ ).
A set of two pressure gauges is used to measure the atmospheric pressure inside and outside the chamber. A MKS Instruments 910 DualTrans ${ }^{\mathrm{TM}}$ transducer is installed inside with a measuring range of $5 \times 10^{-4}$ to $2 \times 10^{3}$ mbar and an accuracy of $\pm 10 \%$ of its reading, in the range of $5 \times 10^{-4}$ to $1 \times 10^{-3} \mathrm{mbar}, \pm 5 \%$ of reading in the range of $10^{-3}$ to $15 \mathrm{mbar}$ and $\pm 0.75 \%$ of reading in the range of 15 to 1000 mbar. The pressure transducer contains two separate sensor elements: a MicroPirani ${ }^{\mathrm{TM}}$ sensor element, based on measurement of thermal conductivity, and a Piezo sensor, based on measurement of the mechanical deflection of a silicon membrane relative to an integrated reference vacuum. The Piezo measures true absolute pressure independent of gas composition and concentration. A Vaisala BAROCAP ${ }^{\circledR}$ Barometer PTB110 is installed outside the chamber with a 


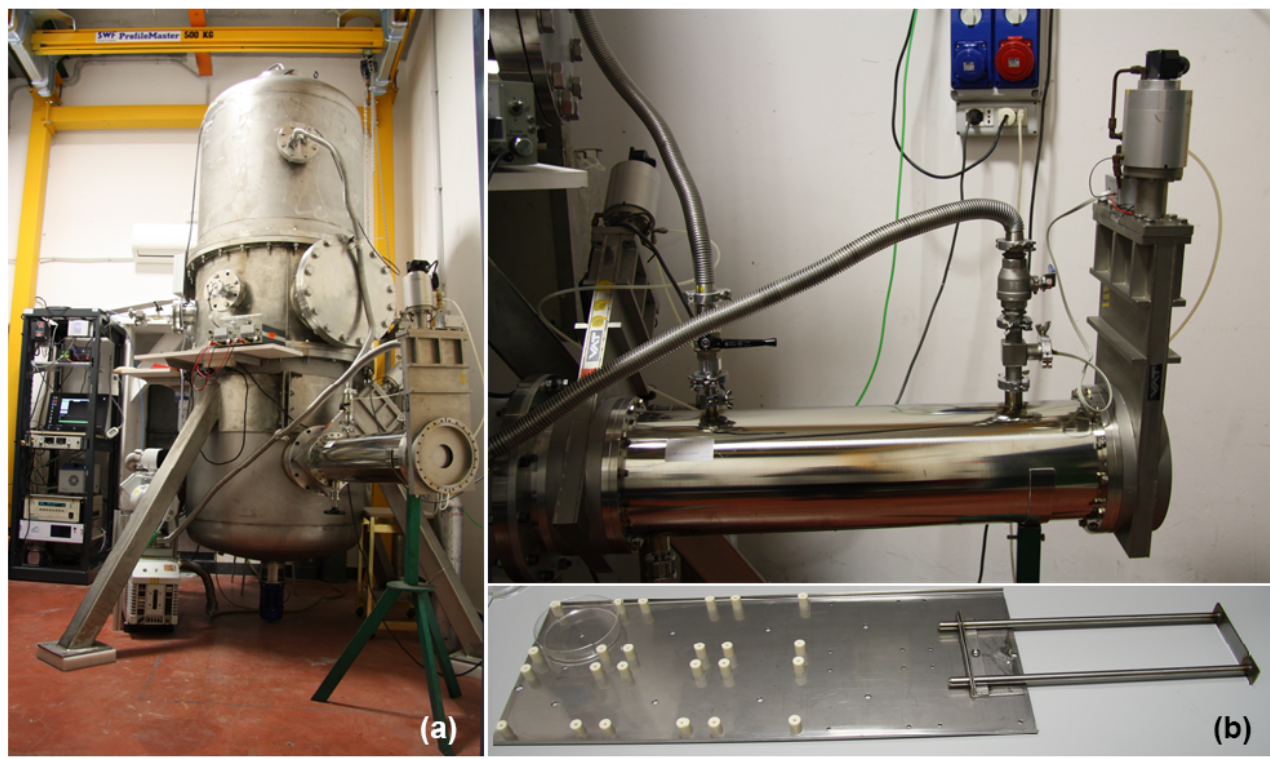

Figure 2. (a) The main structure of ChAMBRe: (b) the cylindrical volume (top), which hosts the sliding tray (bottom), used to introduce up to six Petri dishes (or other objects) inside the main ChAMBRe body.

measuring range of $5 \times 10^{2}$ to $1.1 \times 10^{3}$ mbar and accuracy of \pm 0.3 mbar at $20^{\circ} \mathrm{C}$.

Internal temperature and relative humidity are continuously measured by a HMT334 Vaisala ${ }^{\circledR}$ Humicap ${ }^{\circledR}$ humidity and temperature transmitter for high pressure and vacuum application (up to 100 bars). This sensor is mounted in the upper ISO-K100 flange on the top dome. In the operative range (from 15 to $25^{\circ} \mathrm{C}$ ) the accuracy is $\pm 1 \% \mathrm{RH}(0$ to $40 \% \mathrm{RH})$ and $\pm 1.7 \% \mathrm{RH}$ (90 to $100 \% \mathrm{RH})$ and \pm 0.2 at $20^{\circ} \mathrm{C}$.

All the atmospheric gauges are connected to a NI Compact-RIO acquisition system (based on the NI cRIO9064 controller), which also allows the remote monitoring of the ChAMBRe parameters through an ethernet connection.

Two types of UV lamps are permanently installed inside the chamber. A $90 \mathrm{~cm}$ long lamp is inserted through the flange in the top dome (Fig. 1): it produces a $85 \mathrm{~W}$ UV radiation at $\lambda=253.7 \mathrm{~nm}$ (UV-STYLO-NX, Light Progress srl) which is used to sterilize the chamber volume without producing ozone after any experiment with bio-aerosol, in particular. A second type of lamp, producing UV radiation at $\lambda<240 \mathrm{~nm}$, can be inserted through one of the ISOK100 flanges of the central ring to generate ozone. Two different units of mercury lamps (length $=5 \mathrm{~cm}$, power $=6 \mathrm{~W}$ and length $=20 \mathrm{~cm}$, power $=10 \mathrm{~W}$; both of BHK Incorporated, Analamp models), can bring ozone concentration inside ChAMBRe from zero to about $300 \mathrm{ppb}$ in about 30 or 15 min, respectively.

\subsection{Instruments connected to ChAMBRe}

The large number of free flanges in the main structure gives the possibility of connecting several external instruments to ChAMBRE.

Polydispersed aerosol can be sprayed into the simulation chamber using a Blaustein Atomizer (BLAM, singlejet model, $\mathrm{CH}$ Technologies), connected to the chamber with a curved stainless-steel tube (length $=50 \mathrm{~cm}$, diameter $=1.5 \mathrm{~cm}$ ). The single jet BLAM is specifically designed to provide bio-aerosols with the enhanced viability of microorganisms for aerobiology research (Zhen et al., 2014) with respect to the Collison nebulizer, employed in the pilot test performed by Brotto et al. (2015). The BLAM's viability is essentially due to its efficiency in that it utilizes minimal energy to properly aerosolize a liquid. The single-jet BLAM is used in one-pass mode, where the liquid medium is subjected to the sonic air jet only one time. The atomizing head is composed of two main parts: nozzle body and expansion plate. The atomization occurs when the pressurized air (air flow $2 \mathrm{Lpm}$, pressure $3.8 \mathrm{bar}$ ) pushes at sonic velocity through a precisely laser cut ruby crystal (fixed size 0.010 in. diameter) pressed into the nozzle body, while the liquid with particles is carried into a cavity between the nozzle body and expansion plate at a desired flow rate (liquid feed $=0.4 \mathrm{~mL} \mathrm{~min}^{-1}$ ) using a precision pump (NE-300 Just Infusion $^{\mathrm{TM}}$ Syringe Pump, New Era Pump Systems, Inc.). The properties of the aerosol generated by the single-jet BLAM are a function of the jet hole size, depth of the liquid cavity, and expansion cone size. The atomizer features a modular design, composed of five interchangeable plates, which enables it to accommodate liquids of varying properties to 
produce aerosols in specific size ranges and output concentration, with a nebulization efficiency (i.e. mass ratio between the mass of the produced aerosol to the mass of the solute or of the material suspended in the liquid inserted in the BLAM) between $1 \%$ and $8 \%$. In this work, the expansion plate with a cavity depth and a cone diameter of 0.001 and 0.020 in., respectively, has been used. The accelerated air jet breaks up the liquid into droplets. The aerosol generated by this process is sprayed downwards inside the jar, where the larger droplets are collected on the liquid surface due to impaction as they cannot make the U-turn while the finest droplets are forced up through the outlet tube on top of the BLAM lid. The result is a very fine mist, well within the respirable range (i.e. with diameter smaller than $10 \mu \mathrm{m}$ ) and with narrow size distribution. The size distribution, immediately after the injection of physiological solution (with or without bacteria) in ChAMBRe, shows a mean value of $0.45 \mu \mathrm{m}$ with a standard deviation of $0.25 \mu \mathrm{m}$. This information, however, is just a typical figure since the actual size depend on the solution we nebulize according to the type and concentration of the solute.

Aerosol samplers and multistage cascade impactors can be easily connected through the ISO-K flanges and maintained in operation for times depending on their nominal flow and the needs of the particular experiment (e.g. a typical $10 \mathrm{~L} \mathrm{~min}^{-1}$ device, like the 13-stage rotating NanoMoudiII $^{\mathrm{TM}}$ - Nano-Micro orifice uniform deposit impactor, Model 125B, MSP Corporation; Hwan et al., 2010 - extracts a $10 \%$ of the total chamber volume in about $20 \mathrm{~min}$ ). A similar figure holds for impingers (Flow Impinger by Aquaria srl) which can be filled with $20 \mathrm{~mL}$ of sterile physiological solution. Such devices must be operated at a constant air flow of $12.5 \mathrm{~L} \mathrm{~min}^{-1}$ (e.g. by a low capacity pump: Model LCP5, Copley Scientific).

Particle concentration inside the chamber is measured continuously by two different instruments: a Scanning Mobility Particle Sizer (SMPS, GRIMM Technologies, Inc.) and an Optical Particle Counter (OPC, mod. Envirocheck 1.107, GRIMM Technologies, Inc.).

The SMPS is formed by three components in sequence: a neutralizer (i.e. a bipolar diffusion charger) supplied by Eckert \& Ziegler Cesio (Prague), a differential mobility analyzer (DMA, model 55-U) and a condensation particle counter (CPC, model 5403), both from Grimm GmbH (Ainring, Germany). The neutralizer is based on a radioactive source of ${ }^{241} \mathrm{Am}$ with an activity of $3.7 \mathrm{MBq}$. The DMA is available with two different columns, working alternatively in the size range 5.5-350.4 nm (MDMA), and 11.1-1083.3 nm (LDMA), and classifying particles in 50 dimensional classes. Scanning the voltage through the entire electrical particle mobility range requires about $5 \mathrm{~min}$ with MDMA and about 10 min with LDMA. If necessary (relative humidity $>80 \%$ ), the system is equipped with a dedicated air dryer to be inserted upstream of the DMA. A pre-impactor can be also used to remove particles larger than a fixed upper size limit.
In the CPC, downstream of the DMA, the particle size is increased by $n$-butanol condensation on their surface and then the particles are optically counted. The CPC can also be operated as a standalone unit to measure the total particle concentration, with a response time of $4 \mathrm{~s}$ and a sensitivity to particle size larger than $4.5 \mathrm{~nm}$. The maximum measurable concentration can reach $10^{7}$ particles $\mathrm{cm}^{-3}$. Both the CPC and the SMPS are operated at an air flow of $0.3 \mathrm{~L} \mathrm{~min}^{-1}$ at atmospheric pressure. To prevent possible damage, the inlet is connected to ChAMBRe through a gate valve, which is closed before any evacuation procedure. The SMPS has been connected to ChAMBRe through a smoothly bended pipe in a way to have an horizontal length of about $10 \mathrm{~cm}$ followed by a vertical part of about $30 \mathrm{~cm}$.

The OPC is a Grimm 1.107 - Envirocheck version, which operates in 31 size intervals with diameters in the 0.25 $32 \mu \mathrm{m}$ size range with a $6 \mathrm{~s}$ time resolution. The Grimm OPC uses a dehumidification system which operates when ambient relative humidity is higher than $70 \%$. This optical particle counter has a patented light scattering technique based on an advanced low water sensitive laser source $(\lambda=675 \mathrm{~nm})$. The OPC is factory calibrated via monodisperse latex particles for size classification. The reproducibility of the OPC in particle counting is $\pm 2 \%$ (Putaud et al., 2004). The OPC working flow is $1.2 \mathrm{~L} \mathrm{~min}^{-1}$ and it is connected to ChAMBRe through a gate valve which is closed before emptying the chamber volume. This position allows for sampling that directly sucks from one of the large flanges without any connecting tube.

The ozone concentration is monitored by a M400A Ozone Analyzer from API (Advanced Pollution Instrumentation, Inc.). The M400A uses a system based on the Lambert-Beer law for measuring ozone in ambient air. A $254 \mathrm{~nm}$ UV light signal is passed through the sample cell where it is absorbed in proportion to the amount of the ozone present. Periodically, a switching valve alternates measurement between the sample stream and a sample that has been scrubbed of ozone. The instrument has a sampling rate of $0.8 \mathrm{~L} \mathrm{~min}^{-1}$, a response time of $6 \mathrm{~s}$ and a detection limit of $0.6 \mathrm{ppb}$ (updated UV Photometric Ozone Analyzer, model O342e from Environnement $\mathrm{SA}$ ).

The nitrogen oxides ( $\mathrm{NO}$ and $\mathrm{NO}_{2}$ ) concentrations are monitored by an AC32e, from Environnement SA. The AC32e utilizes the principle of chemiluminescence, which is the standard method for the measurement of $\mathrm{NO}$ and $\mathrm{NO}_{2}$ concentration (EN 1421), for automatically analyzing the NO-NO ${ }_{x}$ and $\mathrm{NO}_{2}$ concentration within a gaseous sample. The analyzer measures the photons emitted after the reaction between $\mathrm{NO}$ and $\mathrm{O}_{3}$. The analyzer initially measures the NO concentration in the sample, through NO ozone oxidation. Subsequently, the sample passes through the heated molybdenum converter, which reduces $\mathrm{NO}_{2}$ to $\mathrm{NO}$ and is then mixed with ozone in the reaction chamber and the resulting NO concentration is determined. In this way, the signal is proportional to the sum of the molecule $\mathrm{NO}$ and $\mathrm{NO}_{2}$ 


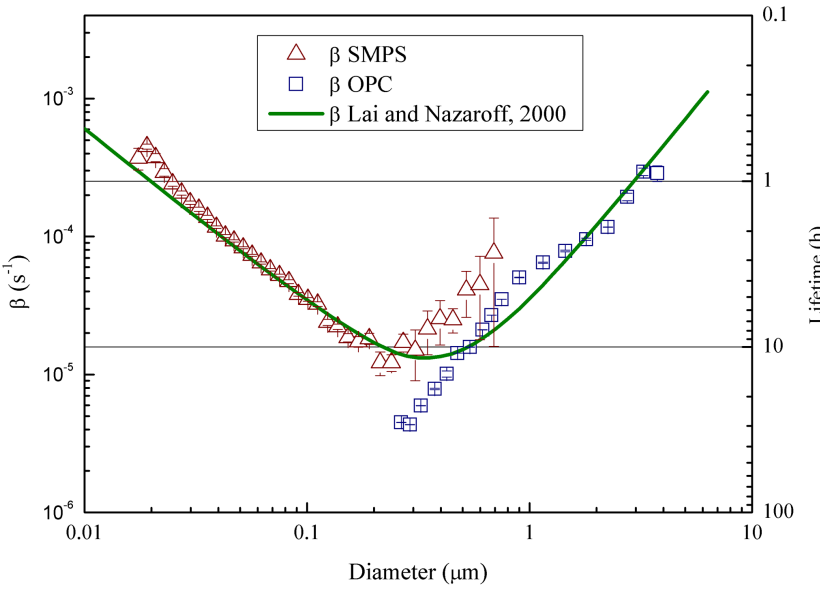

Figure 3. Particle loss coefficient $(\beta)$ and lifetime (secondary vertical axis), vs. aerosol size measured in ChAMBRe by $\mathrm{NaCl}$ salt injection $\left(21^{\circ} \mathrm{C}, 47 \% \mathrm{RH}\right)$. The curve resulting from the Lai and Nazaroff (2000) model is also shown for reference (see text). Error bars include statistical uncertainties only.

(reduced to NO in the converter) in the sample. With a sampling rate of $0.66 \mathrm{~L} \mathrm{~min}^{-1}$ this instrument reaches a detection limit of $0.2 \mathrm{ppb}$ with a response time of $40 \mathrm{~s}$.

\section{Characterization}

\subsection{Aerosol particle lifetime}

Depending on kinetics, processes in the atmosphere have typical reaction times ranging from a few seconds up to several days. For this reason, in the case of simulation chambers, the evaluation of aerosol particle lifetime is of primary importance: it is necessary to keep in suspension enough aerosol for a sufficient time, in order to allow chemical or biological transformations of particles. Aerosol particle lifetime in chambers depends on many factors, e.g. wall losses caused by adsorption or deposition, diffusion and mixing processes, gravitational settling, electrostatic drawing, or all of them combined, depending of course on particle properties (i.e. density, dimensions, shape, and vapour pressure).

For the characterization of particle lifetime in ChAMBRe, the Blaustein Atomizer (BLAM) was used. By feeding the BLAM with saline solutions $\left(\mathrm{NaCl}\right.$ and $\left.\left(\mathrm{NH}_{4}\right)_{2} \mathrm{SO}_{4}\right)$ with different concentration (up to very concentrated solutions, about $10 \mathrm{~g} \mathrm{~L}^{-1}$ ), it is possible to generate polydispersed particles with continuous size distributions from few $\mathrm{nm}$ up to about $5 \mu \mathrm{m}$. During these experiments, the mixing fan was kept on at a constant rotation speed of $5 \mathrm{~Hz}$, this resulting in a mixing time of about 2 min. Thanks to the combined SMPSOPC measurements, the aerosol particle lifetime was measured as a function of particle size (Fig. 3). For each size bin of the two instruments, particle lifetime has been determined by fitting the mass decay curve with a simple first order ex- ponential. Relative humidity in ChAMBRe during the measurements was around $\mathrm{RH}=47 \%$. Aerosol dilution due to the air flow through the two counters (in total: $1.6 \mathrm{~L} \mathrm{~min}^{-1}$ ) was taken into account and properly corrected; the chamber is designed to ensure that the pressure is kept constant: the same amount of clean air is introduced into the chamber through the input from the HEPA filter. The first time interval after each injection, when coagulation could take place, was excluded in the analysis, considering this way the concentration values smaller than $10^{4}$ particle $\mathrm{cm}^{-3}$ only. Results are reasonable and very close to the values in the literature (Lai and Nazaroff, 2000; Cocker et al., 2001; Wang et al., 2011); in particular experimental data are nicely reproduced (i.e. the mean discrepancy between measured and calculated values is around $50 \%$ ) by the wall deposition model described in Lai and Nazaroff (2000) treating ChAMBRe as a rectangular cavity with a friction velocity of ca $6 \mathrm{~cm} \mathrm{~s}^{-1}$ (Fig. 3). Particle lifetime in ChAMBRe varies from a few hours to about 1 day depending on particle size. The uncertainty on particle lifetime plotted in Fig. 3 has been evaluated on a pure statistical basis. Actually, in the size region between 300 and $600 \mathrm{~nm}$, both the SMPS and OPC data could be particularly sensitive to other effects (e.g. background fluctuation for the SMPS, systematic artifacts in the first OPC bins) which have not been fully investigated in this work and that do not change the typical feature depicted in Fig. 3. While nominal particle lifetimes are important parameters to design the experiments in the chamber and their typical time window, their values can actually vary according to the specific characteristics of the injected or formed particles.

\subsection{Ozone and wall reactivity}

The presence of walls obviously influences the chemical and physical dynamics of the experiments carried out inside simulation chambers, as the gaseous species can be lost to the chamber walls. To describe the behaviour of the walls of our chamber, we considered the dark reactivity of ozone, due to its chemical reactivity towards surfaces, its relevance to chamber experiments (as reactant or as sterilization agent) and as atmospheric oxidant.

A series of five experiments have been done with initial concentration ranging from 300 to $1000 \mathrm{ppbv}$. The ozone concentration in the chamber was monitored as a function of time. The pseudo-first-order rate for loss processes is equal to $(3.04 \pm 0.40) \times 10^{-5} \mathrm{~s}^{-1}$ and it is in good agreement with what reported in the literature for other similar facilities (Wang et al., 2011). This parameter is highly dependent on the chamber wall material, on its history, related to the cleaning protocol and the operating conditions such as temperature or relative humidity (Wang et al., 2011). As a consequence, the quantification must be carried on regularly and before each set of experiments for any type of study. 


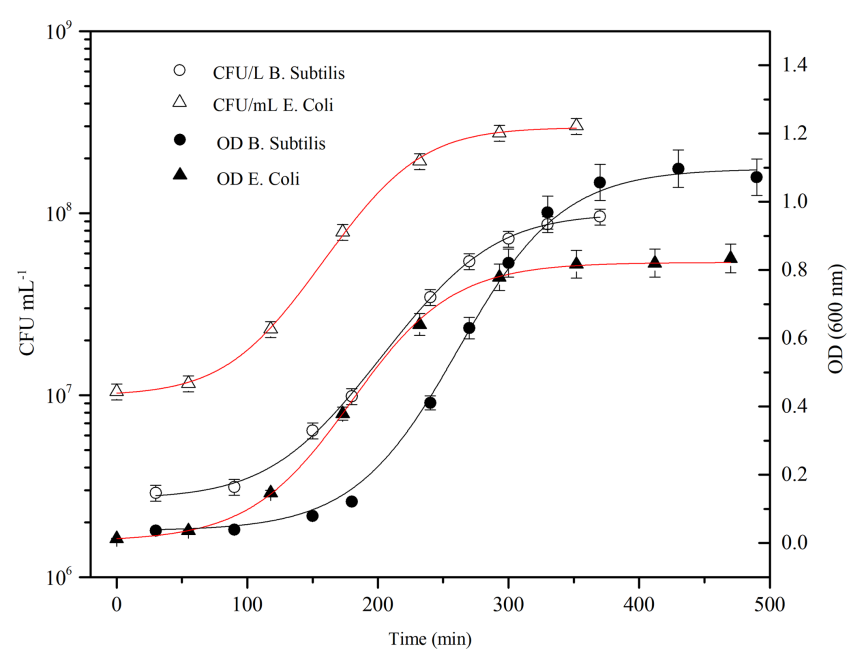

Figure 4. Typical grow curve for Bacillus subtilis (black line, circle) and Escherichia coli (red line, triangle): optical density (OD $600 \mathrm{~nm}$ ) and the corresponding bacteria concentration (CFU ml ${ }^{-1}$ ) are plotted vs. time. Data of concentration curves are reported until the stationary phase.

\subsection{Background levels $\left(\mathrm{PM}, \mathrm{O}_{3}, \mathrm{NO}_{x}\right)$}

The background level of particles inside the chamber was measured by SMPS and OPC. The coupling of the two counters provides a comprehensive picture of the particles inside the chamber ranging from few nm up to 31 microns (for more information; see Sect. 2.3). After each experiment, the chamber is cleaned by a multistep procedure: the UV lamp (see Sect. 2.1) is first switched on for $10 \mathrm{~min}$, the chamber is then evacuated and vented to atmospheric pressure through an HEPA filter (Sect. 2.1). Afterwards, a high ozone concentration $(>500 \mathrm{ppb})$ is produced to be sure to sterilize any part of the set-up possibly not reached before by the UV rays. Finally, the chamber is evacuated and vented again.

Background level measurements performed subsequently to chamber cleaning showed no significant particles presence (i.e. about 2 and 0.5 particle $\mathrm{cm}^{-3}$, respectively, in the SMPS-LDMA and OPC range).

Background concentrations of $\mathrm{O}_{3}$ and $\mathrm{NO}_{x}$, could be introduced in the chamber during the venting after an evacuation, since both the gases can be present in the room air: concentration values measured periodically in the chamber over 4 months turned out to be smaller than 1-2 ppb, i.e. close to the analyser sensitivity (see Sect. 2.3).

\section{Protocols to prepare, inject, expose, and collect bacteria}

The usefulness of ASCs in providing new possibilities for the study of bacteria and other biological particles in air critically depends on the associated protocols, which are essential to

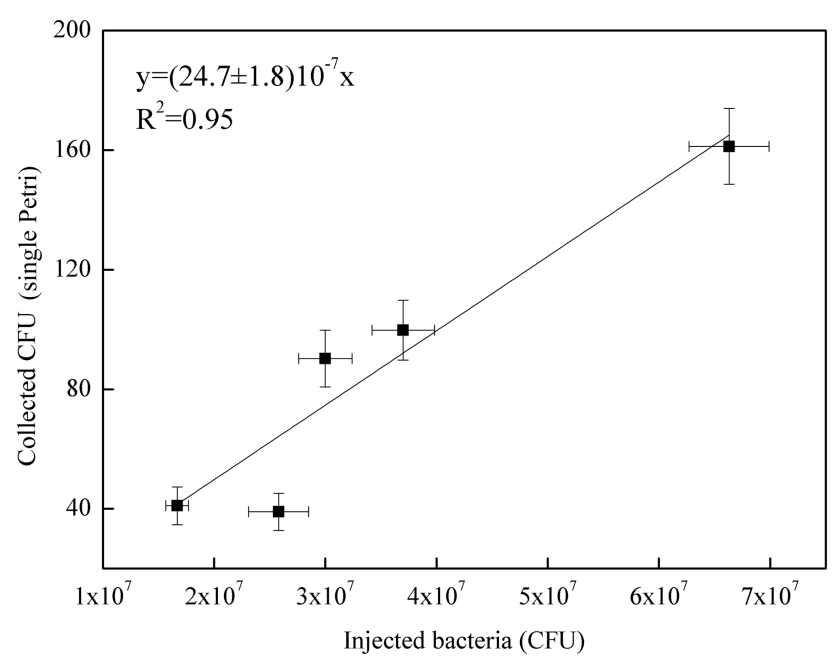

Figure 5. Correlation curve between the number of $B$. subtilis bacteria injected in ChAMBRe (in units of $10^{7} \mathrm{CFU}$ ) and the average count on the four Petri dishes exposed in each experiment.

understand how the bacteria survive and if they are in able to grow and reproduce in the atmospheric conditions of the simulation chamber. In this section we describe the standard methodology developed for the bio-aerosol experiments (injection, collection, and storage) and the related experimental conditions, that should be representative of the typical environmental ones.

\subsection{Bacterial strains}

Experimental procedures involved two strains consisting of Bacillus subtilis (ATCC ${ }^{\circledR} 6633^{\mathrm{TM}}$ ) and Escherichia coli $\left(\right.$ ATCC $^{\circledR} 25922^{\mathrm{TM}}$ ). These microorganisms are extensively used as model organisms in microbiology and molecular biology fundamental and applied studies (Lee et al., 2002).

Bacillus subtilis is a Gram-positive, rod-shaped bacterium with a length ranging between 2.5 and $6.5 \mu \mathrm{m}$. It is commonly found in soils but has been also observed in other environmental matrices such as water and air (Earl et al., 2008). It has a wide commercial use as it is nonpathogenic. B. subtilis serves as a model organism and is considered a reference for cell differentiation and adaptation. This model status makes it one of the most extensively studied organisms in nature given its ability to survive and even thrive in a wide range of harsh environments (Earl et al., 2008).

Escherichia coli is a Gram-negative, rod-shaped, Enterobacter, is about $1-2 \mu \mathrm{m}$ long and about $0.25 \mu \mathrm{m}$ in diameter. It is a common inhabitant of the gastrointestinal tract of warm-blooded animals, including humans, but recent studies have reported that some specific strains of $E$. coli can also survive for long periods of time, and potentially reproduce, in extra-intestinal environments. Escherichia coli is among one of the most studied model organisms. Its fast-growth characteristics under optimal conditions make it suitable as 
host organism for many gene manipulation systems, producing countless enzymes and other industrial products, and to study the evolution of microorganisms (Jang et al., 2017).

\subsection{Preparation of bacterial suspension and injection in ChAMBRe}

Several techniques for bacteria and bio-aerosol characterization are available on site. In the same building that hosts the atmospheric simulation chamber there is a basic microbiology lab equipment allowing for culture analysis in vitro (isolation, identification, growth) and biochemical tests (e.g. catalase and oxidase): autoclave (Asal mod.760), vortex, centrifuge and microcentrifuge (Eppendorf centrifuge 5417R), water purification system Milli-Q (Millipore-Elix), incubator for temperature control Ecocell and Friocell MMM Group, Steril-VBH Compact "microbiological safety" cabinet, Thermo electron corporation steri-cycle HEPA Class 100 incubator; optical microscope (Nikon Eclipse TE300) for bacterial detection and live-dead discrimination by epifluorescence with specific dyes and for immunoassay fluorescence to label the antigenic bacterial target, fluorescent molecule or enzyme. The transfer of bacteria from the biological laboratory to the simulation chamber takes only a few minutes, ensuring a quickly execution of the chamber experiments, once the desired phase of bacteria growth is reached, and then a quick treatment of the samples collected after the experiments in the chamber.

The same culture preparation technique was applied at both the bacterial strains, in order to minimize experimental variations.

Firstly, it is important to ensure the maximum bacteria cells viability prior to the injection. Typically, to understand and define the growth of a particular microbial isolate, cells are placed in a culture medium in which the nutrients and environmental conditions are controlled. If the medium provides all nutrients required for growth and environmental parameters are optimal, a growth curve can be obtained by measuring the increase in bacterial number or mass as a function of time. Different distinct growth phases can be observed within a growth curve: these include the lag phase, the log phase, the stationary phase, and the death phase. Each of these phases represents a distinct period of growth that is associated with typical physiological changes in the cell culture. Therefore, the growth curve for both of bacterial strains was obtained quantifying the rate of change in the number of cells in a culture per unit time thus identifying the midexponential phase (log phase), where the maximum viability of the cells is ensured and the number of dead microorganisms is at minimum. B. subtilis was purchased as water soluble freeze-dried Selectrol discs. The discs were dissolved in sterile Tryptic Soy Broth (TSB), also known as soybean-casein digest medium (SCDM), incubated at $37^{\circ} \mathrm{C}$ for 1 day and then rejuvenated; $E$. coli cells were scraped off agar medium using sterile plastic loops and suspended
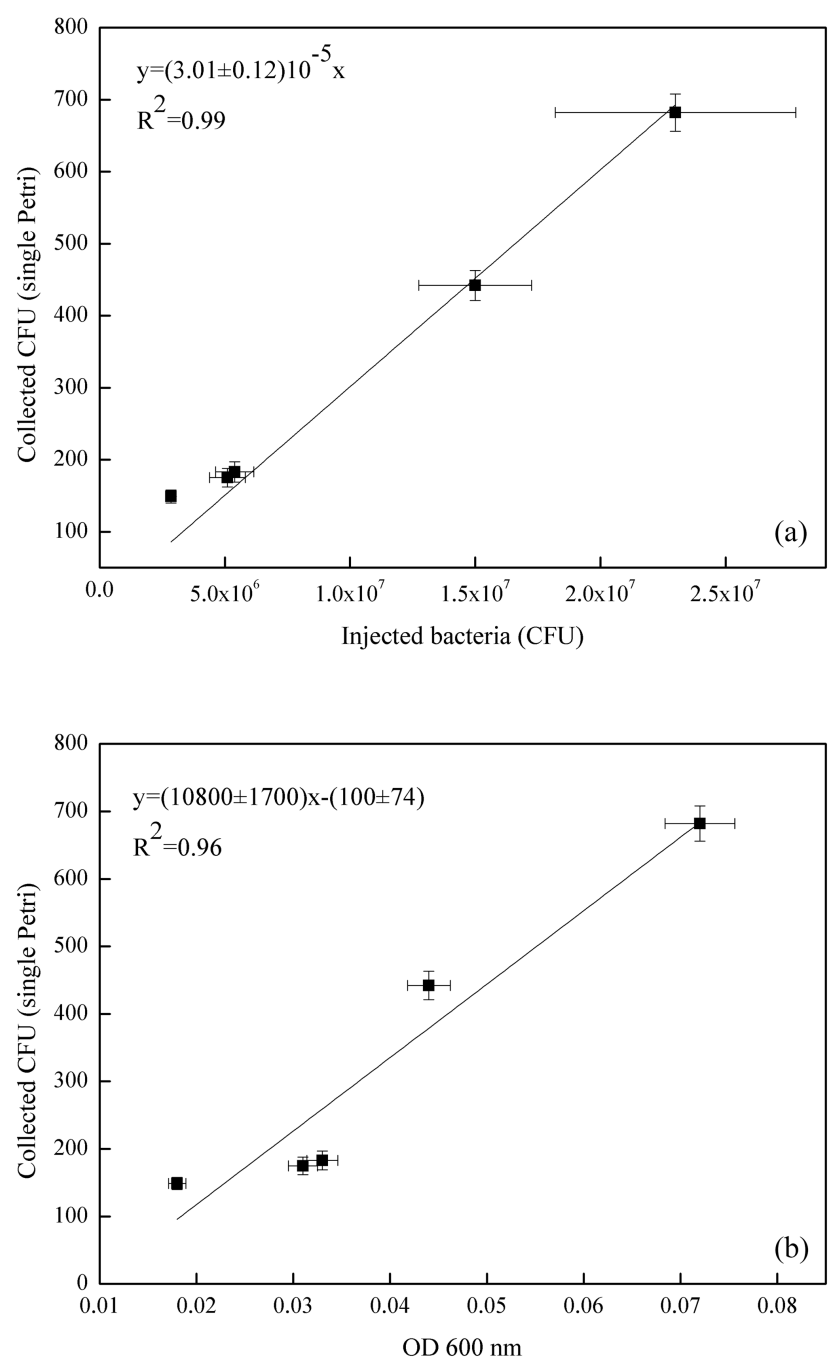

Figure 6. Correlation curve of the average count on the four Petri dishes exposed in each experiment with the number of $E$. coli bacteria injected in ChAMBRe (in units of $10^{7} \mathrm{CFU}, \mathbf{a}$ ) and with the optical density (OD $600 \mathrm{~nm}, \mathbf{b})$.

in sterile culture broth medium. In both cases, the growth curve was then followed, once every hour, with a spectrophotometer V-530 UV-vis (Jasco International Co. Ltd, Hachioji, Japan), where the number of cells per $\mathrm{mL}$ of culture was estimated from the turbidity of the culture. The optical density (OD) of the bacterial solution, measured at a wavelength of $600 \mathrm{~nm}$, is a common method for estimating the concentration of bacterial cells in a liquid. The amount of the light scattered by the microorganisms suspension is an indication of the biomass contents (Sutton, 2011). Data, obtained from spectrophotometric measurements $\left(\mathrm{OD}_{600 \mathrm{~nm}}\right)$ were used to estimate when the mid-exponential phase (corresponding an $\mathrm{OD}_{600 \mathrm{~nm}}$ of 0.5 ) is reached. Actually, the number of cultivable cells was counted as Colony Forming Units (CFU), by standard dilution plating: $100 \mu \mathrm{L}$ of 6 -fold serial dilutions of the solution was spread on an agar non-selective culture 
Table 1. Environmental parameters (RH, $T, P$ ) in ChAMBRe during the experiments with B.subtilis.

\begin{tabular}{lrrrr}
\hline & $\begin{array}{r}\text { Relative humidity } \\
\text { range }(\%)\end{array}$ & $\begin{array}{r}\text { Temperature } \\
\text { range }\left({ }^{\circ} \mathrm{C}\right)\end{array}$ & $\begin{array}{r}\text { Pressure range } \\
(\mathrm{mbar})\end{array}$ & $\begin{array}{r}\text { Petri dishes } \\
\text { exposure time (hh:mm) }\end{array}$ \\
\hline Exp. 1 & $55-85$ & $22.0-21.1$ & $1015-1012$ & $05: 00$ \\
Exp. 2 & $44-71$ & $23.7-24.5$ & 1010 & $05: 20$ \\
Exp. 3 & $50-43$ & $23.2-21.3$ & $1014-1015$ & $05: 15$ \\
Exp. 4 & $44-70$ & $22.0-22.5$ & 1016 & $05: 05$ \\
Exp. 5 & $75-79$ & $20.1-20.8$ & $1005-1007$ & $05: 00$ \\
\hline
\end{tabular}

Table 2. Bacteria concentration (B. subtilis) in the aerosolized solution and average number of colonies counted on one Petri dish.

\begin{tabular}{lrrrr}
\hline & OD $_{600}$ & $\begin{array}{r}\text { Suspension concentration } \\
\left(\mathrm{CFU} \mathrm{mL}^{-1}\right) \times 10^{7}\end{array}$ & $\begin{array}{r}\text { Bacteria injected } \\
\mathrm{CFU} \times 10^{7}\end{array}$ & $\begin{array}{r}\text { Average CFU } \\
\text { collected }\end{array}$ \\
\hline Exp. 1 & $0.57 \pm 0.03$ & $1.85 \pm 0.14$ & $3.70 \pm 0.28$ & $100 \pm 10$ \\
Exp. 2 & $0.58 \pm 0.03$ & $3.32 \pm 0.18$ & $6.63 \pm 0.36$ & $161 \pm 13$ \\
Exp. 3 & $0.58 \pm 0.03$ & $1.50 \pm 0.12$ & $3.00 \pm 0.24$ & $90 \pm 10$ \\
Exp. 4 & $0.50 \pm 0.03$ & $0.86 \pm 0.09$ & $2.58 \pm 0.27$ & $39 \pm 6$ \\
Exp. 5 & $0.40 \pm 0.02$ & $0.83 \pm 0.05$ & $1.67 \pm 0.10$ & $41 \pm 6$ \\
\hline
\end{tabular}

medium, and incubated at $37^{\circ} \mathrm{C}$ for $24 \mathrm{~h}$ before counting the formed colonies. Data, obtained from CFU counting on Petri dishes, were averaged and used to estimate the uncertainty range of the bacterial concentration in the solution. The growth curves for the two strains are reported in Fig. 4. The measured $\mathrm{OD}_{600 \mathrm{~nm}}$ values were fitted with a three-parameter sigmoidal curve (Eq. 1), where Abs is the absorbance, or optical density, measured at $600 \mathrm{~nm}, a$ and $b$ are constants $(B$. subtilis curve, $a$ is $1.1 \pm 0.01, b$ is $38 \pm 2$; E. coli curve, $a$ is $0.83 \pm 0.01$ and $b$ is $41 \pm 1)$.

$\mathrm{Abs}=\frac{a}{1+e^{-\left(\left(t-t_{0}\right) / b\right)}}$

Before each injection we followed the bacterial growth up to the mid-exponential phase, reached in about $4 \mathrm{~h}$, thus allowing the bacteria to enter the exponential phase of growth.

Spectrophotometer measurements were used to achieve the correct dilution and also to provide the first evaluation of bacterial concentration in the solution, which has to be nebulized, as explained below. The suspension was then centrifuged at $3000 \mathrm{rpm}$ for $10 \mathrm{~min}$, the supernatant was discarded and the pellet was evenly vortexed for $1 \mathrm{~min}$ in physiological solution $(\mathrm{NaCl} 0.9 \%)$ before the injection. The cultivable cell concentration was determined following the above-mentioned procedure. The average on CFU counting is used to estimate the uncertainty range of the bacterial concentration in the nebulized solution.

In each experiment, a volume of $10 \mathrm{~mL}$ of the cells suspension, with a concentration of approximately $10^{7} \mathrm{CFU} \mathrm{mL}^{-1}$ for B. subtilis $\left(\mathrm{OD}_{600 \mathrm{~nm}}\right.$ around 0.5 , single values are reported in Table 2) and $10^{6} \mathrm{CFU} \mathrm{mL}^{-1}$ for E. coli, was prepared for nebulization and placed into a syringe. In particular, for $E$. coli, to obtain the final concentration of

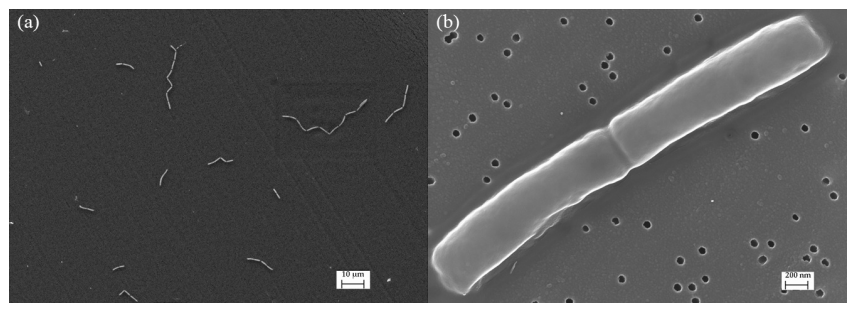

Figure 7. Detail of Bacillus subtilis in physiological solution, magnifications 2000× in panel (a) and 100000× in panel (b).

$10^{6} \mathrm{CFU} \mathrm{mL}^{-1}$, the initial cells suspension with an $\mathrm{OD}_{600 \mathrm{~nm}}$ around 0.6 (single values are reported in Table 4) was diluted $(1: 10,1: 15,1: 20,1: 40)$ before the injection, to avoid an excessive bacterial concentration on the Petri dishes exposed inside the chamber (see Sect. 5.2).

In each experiment, a volume of about 2 or $3 \mathrm{~mL}$ of the cells suspension was sprayed into the simulation chamber using the Blaustein Atomizer (BLAM), described in Sect. 2.3.

\subsection{Collection and extraction methods}

The main body of ChAMBRe is connected through a ISOKF250 pneumatic valve to a cylindrical horizontal volume which is accessible from a second ISO-KF250 gate valve (see Figs. 1 and 2). The two gate valves completely separate the cylinder, which can be connected to the main chamber or alternatively opened without perturbing the ChAMBRe atmosphere. This home-made device has been specifically developed to ensure the insertion and extraction of bioaerosol samplers, in order to minimize the risk of contamination. This volume can be evacuated through a bypass to 
the ChAMBRe main pumping system and can be then refilled to atmospheric pressure both with particle free dry air or through a pipe connected to the ChAMBRe main body. Inside the cylinder, there is a sliding tray which can be inserted in ChAMBRe by a home-made external manual control (Fig. 2) The tray can host up to six Petri dishes (diameter $10 \mathrm{~cm}$, each) which can be inserted in ChAMBRe to collect bacteria (or in general BPAP) directly by deposition onto a proper culture medium. The procedure to insert the Petri dishes in ChAMBRe is organized in consecutive steps (reference to Fig. 1 for the valves names).

1. With V1 closed, the V2 valve is opened to allow the positioning of the Petri dishes (pre-filled with a suitable amount of culture medium) on the sliding tray.

2. Valve V2 is closed and the volume inside the pipe is flushed with clean air coming from the chamber.

3. The atmospheric pressure inside the pipe is recovered by opening the connection to ChAMBRe.

4. V1 is opened and the sliding tray is completely inserted in ChAMBRe.

5. The sterilizing UV lamp (ozone free; see section 2.2) is switched on for $15 \mathrm{~min}$ to guarantee the Petri dishes sterilization.

6. The UV lamp is switched off and ChAMBRe is ready for injection of bacteria.

The chamber sterility before the injection of bacteria was tested through a blank experiment by injecting only sterile physiological solution: no bacterial contamination was observed in the four Petri dishes positioned on the sliding tray.

In a standard experiment, once the bacteria have been injected into ChAMBRe, the Petri dishes remain exposed for the desired time and then the sliding tray can be moved back to the pipe. The ventilation system is on during the exposure period, to maintain a homogeneous distribution of particles inside the chamber volume. Closing V1 and opening V2 the Petri dishes can be removed without perturbing the conditions inside the main chamber. The gravitational settling method has been developed to minimize microbial damage, and has been previously proven to be a very suitable way to collect and count viable bacteria colonies (Brotto et al., 2015). After exposure to the chamber atmosphere, Petri dishes are incubated for $24 \mathrm{~h}$ at $37^{\circ} \mathrm{C}$, after which the number of formed colonies can be counted. It is assumed that the living microorganisms present in the aerosol are deposited on the Petri dishes by gravity without undergoing any stress, from those related to the permanence in the experimental setup atmospheric conditions. In this way, it can be assumed that the number of units forming colonies counted on a Petri dish is proportional to the number of aerosolized and suspended living microorganisms within the chamber and also to the concentration value of viable bacteria in the aerosol.

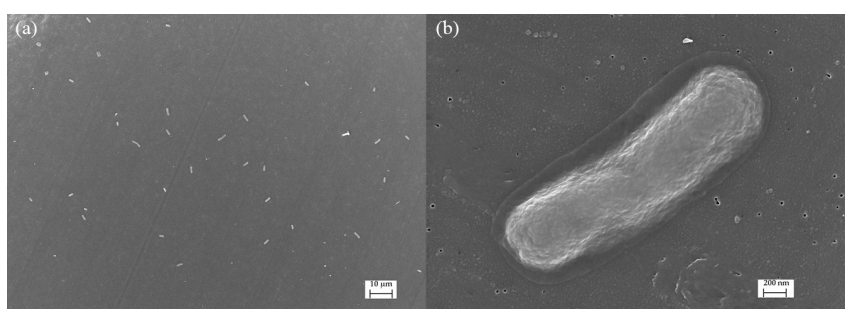

Figure 8. Detail of Escherichia coli in physiological solution, magnifications $2000 \times$ in panel (a) and $100000 \times$ in panel (b).

Lee et al. (2002) suggest that the average aerodynamic diameters of generated $E$. coli and B. subtilis aerosols were 0.63 and $0.75 \mu \mathrm{m}$ respectively. If these data are compared with data obtained with $\mathrm{NaCl}$ solution to determine particles lifetime in chamber, the bacteria lifetime is expected to be around $5 \mathrm{~h}$. The mean global residence time calculated by Burrows et al. (2009b), lie between 2 and 15 days for bacteria traces.

Bacteria from the original liquid suspensions, both in broth and in physiological solution (Sect. 4.2), were also collected on polycarbonate filters (Isopore membrane track-etched filters, pore size $0.05 \mu \mathrm{m}$ ) with a smooth surface, ideal for the study of the morphology of cells and possible bacteria aggregates (e.g. biofilm formation) by scanning electron microscopy (Capannelli et al., 2011). The sampling was performed by exposing filters to the stream of aerosols coming out of the nebulizer, through a secondary port connected to the chamber. For electron microscopy observation the simple protocol adopted here is the following. Bacterial suspensions $(1 \mathrm{~mL})$ were dehydrated and diluted progressively in a graded series of ethanol baths $(30 \%, 50 \%, 70 \%$, and $90 \%)$. This protocol was established by simplifying the standard method named "air drying" (Robinson et al., 1987; Janecek and Kral, 2016), as it was ascertained that the structures of the cells were preserved without requiring the fixation step. Other final treatments (e.g. with tetramethylsilane) were also suppressed as the study of cell ultrastructures was not done in this case as part of the study. Compared with the original suspensions the final dilution is $1: 1000$, in order to reach on the filter an optimal surface density, able to maintain the biological particles well separated. Following this step, the diluted liquid samples were passed through polycarbonate filters held inside a dedicated filter unit (Swinnex $13 \mathrm{~mm}$ filter holder, Millipore Corporation). For each sample, $150 \mu \mathrm{L}$ were loaded with a micropipette onto the filter in the unit, then a syringe was attached to the upper part of the filter holder, in order to filter the sample by pushing gently the plunger. Then the filter was removed and allowed to dry for $3 \mathrm{~h}$. Dry filters were cut in half, mounted on aluminium stubs and sputter coated with carbon before observation by a Field Emission Scanning Electron Microscope (FESEM) Zeiss Supra 40 VP. The selected conditions were as follows: 
Table 3. Environmental parameters (RH, $T, P$ ) in ChAMBRe during the experiments with $E$. coli.

\begin{tabular}{lrrrr}
\hline & $\begin{array}{r}\text { Relative humidity } \\
\text { range }(\%)\end{array}$ & $\begin{array}{r}\text { Temperature } \\
\text { range }\left({ }^{\circ} \mathrm{C}\right)\end{array}$ & $\begin{array}{r}\text { Pressure } \\
\text { range (mbar) }\end{array}$ & $\begin{array}{r}\text { Petri dishes } \\
\text { exposure time (hh:mm) }\end{array}$ \\
\hline Exp. 1 & $75-77$ & $15.8-18.7$ & 994 & $05: 00$ \\
Exp. 2 & $73-77$ & $23.1-23.6$ & $992-999$ & $05: 00$ \\
Exp. 3 & $78-80$ & $19.0-19.3$ & 1010 & $05: 05$ \\
Exp. 4 & $76-83$ & $18.6-19.0$ & $1007-1009$ & $05: 00$ \\
Exp. 5 & $72-80$ & $19.8-20.0$ & $1002-1003$ & $06: 05$ \\
\hline
\end{tabular}

Table 4. Bacteria concentration (E. coli) in the aerosolized solution and average number of colonies counted on one Petri dish.

\begin{tabular}{rrrrrrr}
\hline & $\begin{array}{r}\mathrm{OD}_{600} \\
\text { (before dilution) }\end{array}$ & Dilution factor & $\begin{array}{r}\mathrm{OD}_{600} \\
\text { (after dilution) }\end{array}$ & $\begin{array}{r}\text { Suspension concentration } \\
\left(\mathrm{CFU} \mathrm{mL}{ }^{-1}\right) \times 10^{6}\end{array}$ & $\begin{array}{r}\text { Bacteria injected } \\
\mathrm{CFU} \times 10^{6}\end{array}$ & $\begin{array}{r}\text { Average CFU } \\
\text { collected }\end{array}$ \\
\hline Exp. 1 & $0.57 \pm 0.03$ & $1: 20$ & $0.031 \pm 0.002$ & $2.55 \pm 0.36$ & $5.10 \pm 0.71$ & $175 \pm 13$ \\
Exp. 2 & $0.64 \pm 0.03$ & $1: 10$ & $0.072 \pm 0.004$ & $11.5 \pm 2.40$ & $23.0 \pm 4.8$ & $682 \pm 26$ \\
Exp. 3 & $0.60 \pm 0.03$ & $1: 20$ & $0.033 \pm 0.002$ & $2.70 \pm 0.38$ & $5.39 \pm 0.76$ & $183 \pm 14$ \\
Exp. 4 & $0.65 \pm 0.03$ & $1: 15$ & $0.044 \pm 0.002$ & $7.49 \pm 1.12$ & $15.0 \pm 2.25$ & $442 \pm 21$ \\
Exp. 5 & $0.66 \pm 0.03$ & $1: 40$ & $0.018 \pm 0.001$ & $1.02 \pm 0.07$ & $2.85 \pm 0.20$ & $149 \pm 9$ \\
\hline
\end{tabular}

voltage $10 \mathrm{kV}$, signal in-lens, magnifications ranging from 5000 to $200000 \times$.

\section{First experiments}

Experiments to study the correlation between bacterial viability and the atmospheric composition and conditions in ChAMBRe rely on an assessed protocol to inject and extract bacteria from the chamber. A first set of experiments was therefore devoted to measuring the reproducibility of the whole process with a clean atmosphere (i.e. with the background levels given in Sect. 3.3) inside ChAMBRe.

\subsection{Experiments with $B$. subtilis}

Five different experiments were performed in the period from July and November 2017. The protocol described in Sect. 4 was followed for the bacteria growth, the injection in the chamber and the bacteria collection by four Petri dishes inserted by the sliding tray (Sect. 4.3). Values of the atmospheric parameters in ChAMBRe during each experiment are reported in Table 1. The bacteria concentrations measured in the aerosolized solution and the average number of colonies counted on the Petri dishes after the exposure in ChAMBRe are reported in Table 2. The volume of the bacterial suspension injected through the BLAM atomizer was equal to $2 \mathrm{~mL}$, except during the fourth experiment where the volume was increased to $3 \mathrm{~mL}$ (Table 2). This ensured that the concentration of viable bacteria injected in the chamber was comparable to the values typical of the real atmosphere (Bauer et al., 2003; Burrows et al., 2009b). Taking into account the BLAM nebulization efficiency (Sect. 4.2), the initial aerosol concentration of living microorganisms in ChAMBRe after the in- jection, was estimated to be around $10^{5} \mathrm{CFU} \mathrm{m}^{-3}$. In Table 2, the uncertainties quoted on both injected and collected bacteria are just those deriving from the Poisson fluctuation (i.e. the square root of the number of colonies counted in the Petri dishes) and they do not include any other systematic or statistical contributions. In particular, for the collected CFU, the values reported in Table 2 are the average of the counts of the four Petri dishes exposed in each experiment and that, in each group of four, turned out to be statistically compatible (i.e. within the interval delimited by the statistical uncertainty, the counts in the four Petri dishes were in agreement). Despite these simple assumptions, a good correlation between the number of injected and collected CFU was obtained as shown in Fig. 5. Furthermore, the uncertainty on the slope of the correlation curve turned out to be lower than $10 \%$. This level of reproducibility appears to be adequate to design experiments with different atmospheric conditions (i.e. level of particular pollutants), particularly when compared to the pilot test by Brotto et al. (2015), when much larger variations in the bacteria viability had been observed (see Sect. 1.3). No sizeable effect related to the RH in ChAMBRe was observed (cf. the results of Exp. 4 and 5 in Table 2).

\subsection{Experiments with $E$. coli}

Five different experiments were performed in the period from January and March 2018, following the protocol described in Sect. 4. The values of the atmospheric parameters in ChAMBRe are reported in Table 3. In this set of experiments the relative humidity inside the chamber was increased up to $70 \%$, compared to the environmental value recorded in the laboratory, by changing the working condition of the humidifier (Benbough, 1967; Cox, 1966; Dunklin and Puck, 1947). Es- 
cherichia coli, a Gram-negative bacterium, is more sensitive to the atmospheric conditions inside the chamber than Bacillus subtilis, a Gram-positive strain. As a matter of fact, no CFUs were collected on the Petri dishes positioned inside the chamber when the injection of this strain was performed at low relative humidity $\left(\mathrm{RH} 35 \%, T 20^{\circ} \mathrm{C}\right)$. Furthermore, another experiment showed that injecting $2 \mathrm{~mL}$ of a cell suspension (concentration of approximately $10^{7} \mathrm{CFU} \mathrm{mL}^{-1}$ in physiological solution, $\mathrm{RH} \sim 70 \%$ ) resulted in a huge, uncountable amount of CFUs on the Petri dishes, and suggested that a dilution before the injection was necessary.

The dilution factor, the bacterial concentrations measured in the aerosolized solutions, and the average number of colonies counted on the Petri dishes after the exposure in ChAMBRe are reported in Table 4. It is worth noting that in the experiments discussed in Sect. 5.1, a narrow interval of $\mathrm{OD}_{600 \mathrm{~nm}}$ values, around 0.5, was explored, while in the experiments with $E$. coli, depending on the dilution factor, a larger interval of $\mathrm{OD}_{600 \mathrm{~nm}}$ values was spanned.

The volume of the bacterial suspension injected through the BLAM atomizer was equal to $2 \mathrm{~mL}$ in the first four experiments and was increased to $2.8 \mathrm{~mL}$ in the fifth experiment (Table 4). Figure 6 shows the correlation between the number of injected and collected CFU (top panel), indicating that the uncertainty on the slope of the correlation curve (about $4 \%$ ) was even better than the same uncertainty related to $B$. subtilis (about $7 \%$, Fig. 5). In Fig. 6, the good correlation between the relative optical density of the cell suspensions and the collected CFU (bottom panel) is also shown. For $E$. coli suspension, the evaluation of the microbial concentration through the fast and simpler control of the optical density, seems to possibly be accurate enough to perform controlled experiments, provided an adequate calibration of the whole procedure is carried out.

Although for this bacterial strain a less concentrated solution was injected, more CFUs were collected on the Petri dishes placed inside the chamber. This result could depend on the fact that the humidity in the chamber was generally greater in the second set of experiments providing Gramnegative microorganisms with a more comfortable environment, but also it could depend on the behaviour of the two different bacteria strains.

The FESEM micrographs (Figs. 7 and 8) of the bacteria contained in the liquid suspensions before injection (see Sect. 4.3) clearly show that the cells of $B$. subtilis tend to aggregate, forming long chains (Fig. 7a), while the cells of $E$. coli are mainly present as single individuals (Fig. 8a). Therefore, in the first case it is quite possible that the colonies counted on the Petri dishes originated from a group of cells, while in the second case each colony results presumably from a single viable microorganism.

\section{Conclusions}

A new atmospheric simulation chamber, ChAMBRe, has been installed at INFN-Genoa. The facility has been designed to perform experimental studies on primary biological aerosol particles and bacteria in particular. The performance of the new chamber, which may impact on the future experiments on bio-aerosol (i.e. wall reactivity, aerosol particle lifetime, background levels), has been quantitatively assessed. Furthermore, a protocol to handle the injection and extraction phases has been thoroughly tested both with Gram-positive and Gram-negative bacterial strains. With a clean atmosphere maintained inside ChAMBRe, the ratio between injected and extracted viable bacteria turned out to be reproducible at a $10 \%$ level. Such a result is the first methodological step in view of a forthcoming systematic study of the correlation between bacterial viability and pollution levels. Resident times of viable bacteria in ChAMBre are less than $5 \mathrm{~h}$, much shorter than the generic residence time in the open atmosphere. However, previous literature studies (Brotto et al., 2015) suggest that such a time window is long enough to observe the effects (i.e. viability change) of bacteria exposure to air pollutants. The assessment of such effects is objective of the forthcoming studies at ChAMBRe.

Data availability. The EUROCHAMP-2020 consortium has a data center where every piece of information produced by members is stored and available to everyone. The link is as follows: https://data.eurochamp.org/data-access/chamber-experiments/ (last access: 23 October 2018).

Author contributions. DM, PB, FP, and PP designed and built ChAMBRE; DM, SGD, and PP ran all the injections with bacteria; SGD, EG, ADC, and LV took care of all the biological issues and measurements; AC, CC, LN, and MO performed the SMPS measurements and the FESEM analyses; DM, SGD, CC, MO, JFD, PF, and $\mathrm{PP}$ performed the measurements to assess the aerosol lifetime in ChAMBRe and the wall reactivity; FF designed and implemented the acquisition software; JFD and PF provided advice from their long-standing expertise in the field; DM, SGD, CC, EG, and PP prepared the article with contributions from all of the other authors.

Competing interests. The authors declare that they have no conflict of interest.

Acknowledgements. This project has received funding from the European Union's Horizon 2020 research and innovation programme through the EUROCHAMP-2020 Infrastructure Activity under grant agreement no. 730997. The Authors are indebted to the technical staff of INFN-Genoa for the intense and talented electro-mechanical work. Jean François Doussin wishes to thank the Physics department of the University of Genoa for granting scientific invitations that have allowed its participa- 
tion to this work. The authors wish to thank Houssni Lamkadam and Claudia Di Biagio (LISA) for the Lai and Nazaroff calculations.

Edited by: Johannes Schneider

Reviewed by: two anonymous referees

\section{References}

Amato, P., Parazols, M., Sancelme, M., Laj, P., Mailhot, G., and Delort, A. M.: Microorganisms isolated from the water phase of tropospheric clouds at the Puy de Dôme: major groups and growth abilities at low temperatures, FEMS Microbiol. Ecol., 59, 242254, https://doi.org/10.1111/j.1574-6941.2006.00199.x, 2007.

Amato, P., Joly, M., Schaupp, C., Attard, E., Möhler, O., Morris, C. E., Brunet, Y., and Delort, A.-M.: Survival and ice nucleation activity of bacteria as aerosols in a cloud simulation chamber, Atmos. Chem. Phys., 15, 6455-6465, https://doi.org/10.5194/acp15-6455-2015, 2015.

Ariya, P., Nepotchatykh, O., Ignatova, O., and Amyot, M.: Microbiological degradation of atmospheric organic compounds, Geophys. Res. Lett., 29, 2077, https://doi.org/10.1029/2002GL015637, 2002.

Ariya, P. A. and Amyot, M.: New Directions: The role of bioaerosols in atmospheric chemistry and physics, Atmos. Environ., 38, 1231-1232, https://doi.org/10.1016/j.atmosenv.2003.12.006, 2004.

Ariya, P. A., Sun, J., Eltouny, N. A., Hudson, E. D., Hayes, C. T., and Kos, G.: Physical and chemical characterization of bioaerosols - Implications for nucleation processes, Int. Rev. Phys. Chem., 28, 1-32, 2009.

Bauer, H., Giebl, H., Hitzenberger, R., Kasper-Giebl, A., Reischl, G., Zibuschka, F., and Puxbaum, H.: Airborne bacteria as cloud condensation nuclei, J. Geophys. Res.-Atmos., 108, 4658, https://doi.org/10.1029/2003JD003545, 2003.

Becker, K. H.: Overview on the Development of Chambers for the Study of Atmospheric Chemical Processes, in: Environmental Simulation Chambers: Application to Atmospheric Chemical Processes, edited by: Barnes I. and Rudzinski K. J., Springer, Amsterdam, 1-26, 2006.

Benbough, J. E.: Death Mechanisms in Airborne Escherichia coli, Microbiology+, 47, 325-333, https://doi.org/10.1099/0022128747-3-325, 1967.

Benz, S., Megahed, K., Möhler, O., Saathoff, H., Wagner, R., and Schurath, U.: T-dependent rate measurements of homogeneous ice nucleation in cloud droplets using a large atmospheric simulation chamber, J. Photoch. Photobio. A, 176, 208-217, 2005.

Bowers, R. M., McLetchie, S., Knight, R., and Fierer, N.: Spatial variability in airborne bacterial communities across land-use types and their relationship to the bacterial communities of potential source environments, Isme J., 5, 601-612, 2010.

Brodie, E. L., DeSantis, T. Z., Parker, J. P. M., Zubietta, I. X., Piceno, Y. M., and Andersen, G. L.: Urban aerosols harbor diverse and dynamic bacterial populations, P. Natl. Acad. Sci. USA, 104, 299-304, 2007.

Brotto, P., Repetto, B., Formenti, P., Pangui, E., Livet, A., Bousserrhine, N., Martini, I., Varnier, O., Doussin, J.-F., and Prati, P.: Use of an atmospheric simulation chamber for bioaerosol investigation: a feasibility study, Aerobiologia, 31, 445-455, 2015.
Bundke, U., Reimann, B., Nillius, B., Jaenicke, R., and Bingemer, H.: Development of a Bioaerosol single particle detector (BIO IN) for the Fast Ice Nucleus CHamber FINCH, Atmos. Meas. Tech., 3, 263-271, https://doi.org/10.5194/amt-3263-2010, 2010.

Burrows, S. M., Elbert, W., Lawrence, M. G., and Pöschl, U.: Bacteria in the global atmosphere - Part 1: Review and synthesis of literature data for different ecosystems, Atmos. Chem. Phys., 9, 9263-9280, https://doi.org/10.5194/acp-9-9263-2009, 2009a.

Burrows, S. M., Butler, T., Jöckel, P., Tost, H., Kerkweg, A., Pöschl, U., and Lawrence, M. G.: Bacteria in the global atmosphere - Part 2: Modeling of emissions and transport between different ecosystems, Atmos. Chem. Phys., 9, 9281-9297, https://doi.org/10.5194/acp-9-9281-2009, 2009b.

Capannelli, G., Castello, E., Comite, A., Costa, C., and Mamolini, G.: Electron microscopy characterization of airborne micro- and nanoparticulate matter, J. Electron. Microsc., 60, 117-131, 2011.

Carter, W. P. L., Cocker, D. R., Fitz, D. R., Malkina, I. L., Bumiller, K., Sauer, C. G., Pisano, J. T., Bufalino, C., and Song, C.: A new environmental chamber for evaluation of gas-phase chemical mechanisms and secondary aerosol formation, Atmos. Environ., 39, 7768-7788, 2005.

Chou, C.: Investigation of ice nucleation properties onto soot, bioaerosol and mineral dust during different measurement campaigns, ETH, https://doi.org/10.3929/ethz-a-006541204, 2011.

Cocker, D. R., Flagan, R. C., and Seinfeld, J. H.: State-of-the-Art Chamber Facility for Studying Atmospheric Aerosol Chemistry, Environ. Sci. Technol., 35, 2594-2601, 2001.

Cox, C. S.: The Survival of Escherichia coli sprayed into Air and into Nitrogen from Distilled Water and from Solutions of Protecting Agents, as a Function of Relative Humidity, Microbiology+, 43, 383-399, https://doi.org/10.1099/00221287-43-3-383, 1966.

Deguillaume, L., Leriche, M., Amato, P., Ariya, P. A., Delort, A.M., Pöschl, U., Chaumerliac, N., Bauer, H., Flossmann, A. I., and Morris, C. E.: Microbiology and atmospheric processes: chemical interactions of primary biological aerosols, Biogeosciences, 5, 1073-1084, https://doi.org/10.5194/bg-5-1073-2008, 2008.

Després, V. R., Huffman, J. A., Burrows, S. M., Hoose, C., Safatov, A. S., Buryak, G., Fröhlich-Nowoisky, J., Elbert, W., Andreae, M. O., Pöschl, U., and Jaenicke, R.: Primary biological aerosol particles in the atmosphere: a review, Tellus B, 64, 15598, https://doi.org/10.3402/tellusb.v64i0.15598, 2012.

Dunklin, E. W. and Puck, T. T.: The lethal effect of relative humidity on air-borne bacteria, J. Exp. Med., 87, 87-101, 1948.

Earl, A. M., Losick, R., and Kolter, R.: Ecology and genomics of Bacillus subtilis, Trends Microbiol., 16, 269, https://doi.org/10.1016/j.tim.2008.03.004, 2008.

Fahlgren, C., Bratbak, G., Sandaa, R.-A., Thyrhaug, R., and Zweifel, U. L.: Diversity of airborne bacteria in samples collected using different devices for aerosol collection, Aerobiologia, 27, 107-120, https://doi.org/10.1007/s10453-010-9181z, 2011.

Finlayson-Pitts, B. J. and Pitts Jr., J. N.: Chemistry of the upper and lower atmosphere: Theory, experiments and applications, Academic Press, San Diego, CA, 2000.

Gandolfi, I., Bertolini, V., Ambrosini, R., Bestetti, G., and Franzetti, A.: Unravelling the bacterial diversity in the at- 
mosphere, Appl. Microbiol. Biotechnol., 97, 4727-4736, https://doi.org/10.1007/s00253-013-4901-2, 2013.

Georgakopoulos, D. G., Després, V., Fröhlich-Nowoisky, J., Psenner, R., Ariya, P. A., Pósfai, M., Ahern, H. E., Moffett, B. F., and Hill, T. C. J.: Microbiology and atmospheric processes: biological, physical and chemical characterization of aerosol particles, Biogeosciences, 6, 721-737, https://doi.org/10.5194/bg-6721-2009, 2009.

Ghosh, B., Lal, H., and Srivastava, A.: Review of bioaerosols in indoor environment with special reference to sampling, analysis and control mechanisms, Environ. Int., 85, 254-272, https://doi.org/10.1016/j.envint.2015.09.018, 2015.

Goudie, A. S. and Middleton, N. J.: Desert Dust in the Global System, Springer, Berlin, Heidelberg, 2006.

Griffin, D. W.: Atmospheric Movement of Microorganisms in Clouds of Desert Dust and Implications for Human Health, Clin. Microbiol. Rev., 20, 459-477, 2007.

Griffiths, W. D., Stewart, I. W., Clark, J. M., and Holwill, I. L.: Procedures for the characterisation of bioaerosol particles, Part II: Effects of environment on culturability, Aerobiologia, 17, 109119,2001

Ho, J., Spence, M., and Ogston, J.: Characterizing biological aerosol in a chamber: An approach to estimation of viable organisms in a single biological particle, Aerobiologia, 17, 301-312, 2001

Hoose, C., Kristjánsson, J. E., and Burrows, S. M.: How important is biological ice nucleation in clouds on a global scale?, Environ. Res. Lett., 5, 024009, https://doi.org/10.1088/17489326/5/2/024009, 2010

Hwan, K. K., Kazuhiko, S., Shinji, K., Kazuhiko, S., Mitsuhiko, H., Masami, F., Yoshio, O., and Naoko, T.: Performance Test of an Inertial Fibrous Filter for Ultrafine Particle Collection and the Possible Sulfate Loss when Using an Aluminum Substrate with Ultrasonic Extraction of Ionic Compounds, Aerosol Air Qual. Res., 10, 616-624, 2010.

Janecek, M. and Kral, R.: Modern Electron Microscopy in Physical and Life Sciences, InTech, Rijeka, 2016.

Jang, J., Hur, H., Sadowsky, M., Byappanahalli, M., Yan, T. and Ishii, S.: Environmental Escherichia coli: ecology and public health implications - a review, J. Appl. Microbiol., 123, 570581, https://doi.org/10.1111/jam.13468, 2017.

Jones, A. M. and Harrison, R. M.: The effects of meteorological factors on atmospheric bioaerosol concentrations - a review, Sci. Total Environ., 326, 151-180, 2004.

Kellogg, C. A. and Griffin, D. W.: Aerobiology and the global transport of desert dust, Trends Ecol. Evol., 21, 638-644, 2006.

Lai, A. C. K. and Nazaroff, W. W.: Modeling indoor particle deposition from turbulent flow onto smooth surfaces, J. Aerosol Sci., 31, 463-476, 2000.

Lee, B. U., Kim, S. H., and Kim, S. S.: Hygroscopic growth of E. coli and B. subtilis bioaerosols, J. Aerosol Sci., 33, 1721-1723, 2002.

Lee, S.-H., Lee, H.-J., Kim, S.-J., Lee, H. M., Kang, H., and Kim, Y. P.: Identification of airborne bacterial and fungal community structures in an urban area by T-RFLP analysis and quantitative real-time PCR, Sci. Total Environ., 408, 1349-1357, 2010.

Levin, M. A., Shahamat, M., Shahamat, Y., Stelma, G., and Colwell, R. R.: Design, construction, and evaluation of a chamber for aerobiology, Aerobiologia, 13, 1-6, 1997.
Li, C. S. and Lin, Y. C.: Sampling performance of impactors for bacterial bioaerosols, Aerosol Sci. Technol., 30, 280-287, 1999.

Lighthart, B.: The ecology of bacteria in the alfresco atmosphere, FEMS Microbiol. Ecol., 23, 263-274, 1997.

Lighthart, B.: Mini-review of the concentration variations found in the alfresco atmospheric bacterial populations, Aerobiologia, 16, 7-16, 2000.

Maki, T., Kakikawa, M., Kobayashi, F., Yamada, M., Matsuki, A., Hasegawa, H., and Iwasaka, Y.: Assessment of composition and origin of airborne bacteria in the free troposphere over Japan, Atmos. Environ., 74, 73-82, 2013.

Meola, M., Lazzaro, A., and Zeyer, J.: Bacterial Composition and Survival on Sahara Dust Particles Transported to the European Alps, Front. Microbiol., 6, 1454, https://doi.org/10.3389/fmicb.2015.01454, 2015.

Möhler, O., Georgakopoulos, D. G., Morris, C. E., Benz, S., Ebert, V., Hunsmann, S., Saathoff, H., Schnaiter, M., and Wagner, R.: Heterogeneous ice nucleation activity of bacteria: new laboratory experiments at simulated cloud conditions, Biogeosciences, 5, 1425-1435, https://doi.org/10.5194/bg-5-1425-2008, 2008.

Nava, S., Becagli, S., Calzolai, G., Chiari, M., Lucarelli, F., Prati, P., Traversi, R., Udisti, R., Valli, G., and Vecchi, R.: Saharan dust impact in central Italy: An overview on three years elemental data records, Atmos. Environ., 60, 444-452, 2012.

Parikh, H. M., Jeffries, H. E., Sexton, K. G., Luecken, D. J., Kamens, R. M., and Vizuete, W.: Evaluation of aromatic oxidation reactions in seven chemical mechanisms with an outdoor chamber, Environ. Chem., 10, 245-259, 2013.

Pasteur, L.: Mémoire sur les corpuscules organisés qui existent dans l'atmosphère, Annales de Chimie et de Physique, 3rd series, 64, 1862.

Pearson, C., Littlewood, E., Douglas, P., Robertson, S., Gant, T. W., and Hansell, A. L.: Exposures and Health Outcomes in Relation to Bioaerosol Emissions From Composting Facilities: A Systematic Review of Occupational and Community Studies, J. Toxicol. Env. Heal. B, 18, 43-69, https://doi.org/10.1080/10937404.2015.1009961, 2015.

Prospero, J. M., Blades, E., Mathison, G., and Naidu, R.: Interhemispheric transport of viable fungi and bacteria from Africa to the Caribbean with soil dust, Aerobiologia, 21, 1-19, 2005.

Putaud, J.-P., Van Dingenen, R., Dell'Acqua, A., Raes, F., Matta, E., Decesari, S., Facchini, M. C., and Fuzzi, S.: Size-segregated aerosol mass closure and chemical composition in Monte Cimone (I) during MINATROC, Atmos. Chem. Phys., 4, 889-902, https://doi.org/10.5194/acp-4-889-2004, 2004.

Reponen, T., Willeke, K., Grinshpun, S., and Nevalainen, A.: Biological particle sampling, in: Bioaerosol handbook, edited by: Cox, C. S. and Wathes, C. M., 751-778, Boca Raton, FL, CRCPress, 1995.

Ribeiro, H., Duque, L., Sousa, R., and Abreu, I.: Ozone effects on soluble protein content of Acer negundo, Quercus robur and Platanus spp. pollen, Aerobiologia, 29, 443-447, 2013.

Robinson, D. G., Ehlers, U., Herken, R., Herrmann, B., Mayer, F., and Schürmann, F. W.: Methods of Preparation for Electron Microscopy, 1 edn., Springer-Verlag Berlin Heidelberg, XVIII, 190 pp., 1987.

Sala Ferré, M. R., Arias, C., Oliva, J. M., Pedrol, A., García, Pellicer, T., Roura, P., and Domínguez, A.: A community outbreak of Legionnaires' disease associated with a cooling tower in Vic 
and Gurb, Catalonia (Spain) in 2005, Eur. J. Clin. Microbiol., 28, 153, https://doi.org/10.1007/s10096-008-0603-6, 2009.

Samake, A., Uzu, G., Martins, J. M. F., Calas, A., Vince, E., Parat, S., and Jaffrezo, J. L.: The unexpected role of bioaerosols in the Oxidative Potential of PM, Sci. Rep., 7, 10978, https://doi.org/10.1038/s41598-017-11178-0, 2017.

Sousa, R., Duque, L., Duarte, A. J., Gomes, C. R., Ribeiro, H., Cruz, A., Esteves da Silva, J. C. G., and Abreu, I.: In Vitro Exposure of Acer negundo Pollen to Atmospheric Levels of $\mathrm{SO}_{2}$ and $\mathrm{NO}_{2}$ : Effects on Allergenicity and Germination, Environ. Sci. Technol., 46, 2406-2412, 2012.

Sutton, S.: Measurement of microbial cells by optical density, J. Valid. Technol., 17, 46-49, 2011.

Tang, J. W.: The effect of environmental parameters on the survival of airborne infectious agents, J. R. Soc. Interface, 6, 737-746, 2009.

Urbano, R., Palenik, B., Gaston, C. J., and Prather, K. A.: Detection and phylogenetic analysis of coastal bioaerosols using culture dependent and independent techniques, Biogeosciences, 8, 301-309, https://doi.org/10.5194/bg-8-301-2011, 2011.

Van Leuken, J. P. G., Swart, A. N., Havelaar, A. H., Van Pul, A., Van der Hoek, W., and Heederik, D.: Atmospheric dispersion modelling of bioaerosols that are pathogenic to humans and livestock - A review to inform risk assessment studies, Microbial Risk Analysis, 1, 19-39, 2016.
Wagner, R., Bunz, H., Linke, C., Möhler, O., Naumann, K.-H., Saathoff, H., Schnaiter, M., and Schurath, U.: Chamber Simulations of Cloud Chemistry: The AIDA Chamber, in: Environmental Simulation Chambers: Application to Atmospheric Chemical Processes, edited by: Barnes I. and Rudzinski K. J., Nato Science Series: IV: Earth and Environmental Science, Dordrecht, 67-82, https://doi.org/10.1007/1-4020-4232-9_5, 2006.

Wang, J., Doussin, J. F., Perrier, S., Perraudin, E., Katrib, Y., Pangui, E., and Picquet-Varrault, B.: Design of a new multi-phase experimental simulation chamber for atmospheric photosmog, aerosol and cloud chemistry research, Atmos. Meas. Tech., 4, 2465-2494, https://doi.org/10.5194/amt-4-2465-2011, 2011.

Zhao, Y., Aarnink, A. J. A., De Jong, M. C. M., and Groot Koerkamp, P. W. G.: Airborne Microorganisms From Livestock Production Systems and Their Relation to Dust, Crit. Rev. Env. Sci. Tec., 44, 1071-1128, 2014.

Zhen, H., Han, T., Fennell, D. E., and Mainelis, G.: A systematic comparison of four bioaerosol generators: Affect on culturability and cell membrane integrity when aerosolizing Escherichia coli bacteria, J. Aerosol Sci., 70, 67-79, 2014. 